\title{
Laudos arbitrales de la Cámara de Comercio de Neiva: justicia privada, precedentes en la última década 2000 a 2010
}

\section{Arbitration Awards Uttered by the Chamber of Commerce of Neiva: private justice, legal precedents for the decade 2000-2010}

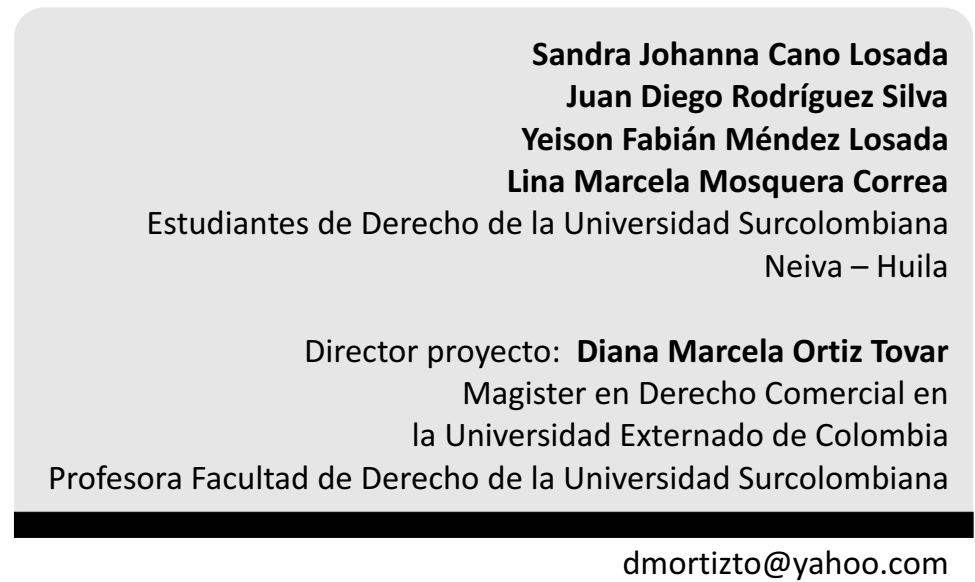

RESUMEN

La presente investigación se origina a partir de los pronunciamientos judiciales proferidos por los Tribunales de Arbitramento cuya sede tuvo lugar en el Centro de Conciliación, Arbitraje y Amigable Composición de la Cámara de Comercio de Neiva, entre los años 2000 a 2010, con el fin de establecer la existencia de precedentes judiciales en áreas del derecho arbitrables por naturaleza.

Los laudos emitidos por los distintos Tribunales formados en el periodo en comento, constituyen por tanto el eje central de este análisis por ser fuente primaria para la consecución de líneas jurisprudenciales en áreas sujetas a arbitraje, además de servir como herramienta útil para que tanto el litigante, estudiante, como funcionario judicial se instruyan acerca de esta justicia especializada.

\section{PALABRAS CLAVES}

Pacto Arbitral, Competencia, Arbitro, Tribunal de Arbitramento, Laudo.

\section{ABSTRACT}

The following research aims at the determination of judicial precedents in legal areas that are subject to arbitration. We limit our analysis to those arbitration awards that have been uttered by the Centre for the Conciliation, Arbitration and Amicable Composition of the Chamber of Commerce of Neiva between 2000 and 2010. Consequently, we provide law students, legal practitioners, and judicial servants with useful tool for a better understanding of such a specialized source of justice. 


\section{KEYWORDS}

Arbitration Agreement, Competence, Arbitrator, Arbitration Tribunal, Arbitration Award

\section{INTRODUCCIÓN}

El arbitraje como Método de Resolución de Conflicto, ya había sido incorporado al ordenamiento jurídico colombiano con antelación a la promulgación de la nueva Carta Constitucional. En 1970 fue introducido al Código de Procedimiento Civil y en 1971 al Código de Comercio; luego, mediante Decreto 2279 de 1989 se estableció el estatuto arbitral, el cual reglamentó en forma completa su procedimiento y derogó las normas anteriores.

La Ley 23 de 1991, de descongestión judicial, creó una clasificación de Tribunales y el Decreto Reglamentario 2651 de 1991, modificó su procedimiento; en 1996, con la Ley 270, Estatutaria de la Administración de Justicia, se permite el establecimiento de mecanismos diferentes al proceso judicial para la solución de los conflictos. Dos años después, por atribuciones otorgadas al ejecutivo, en virtud al artículo 166 de la Ley 446 de 1998, se expidió el Decreto 1818 de 1998, a través del cual se estableció en forma definitiva el Estatuto de los Mecanismos Alternativos de Solución de Conflictos, norma aplicable hoy al trámite arbitral.

Como se observa en su desarrollo legislativo, el arbitraje es un verdadero proceso judicial, con algunos elementos relevantes que lo diferencian del trámite que sigue la denominada jurisdicción ordinaria, así lo entiende la Corte Constitucional Colombiana en sentencia T-244 de 2007, al indicar que este método es de naturaleza procesal. El mismo sentido comparte Azula Camacho (1998), por cuanto es un proceso que tramitan y deciden los particulares, denominados árbitros, quienes quedan investidos transitoriamente de jurisdicción, desde que se constituye el Tribunal hasta cuando el laudo queda ejecutoriado.

El procedimiento arbitral es esencialmente jurisdiccional, es decir, tiene la facultad de administrar justicia tal como lo hace el aparato judicial Estatal, pero por un procedimiento privado y autónomo de este, lo cual permite plantear como hipótesis la formación de precedentes jurídicos en litigios similares, y en consecuencia la viable creación de líneas jurisprudenciales tales como las desarrolladas por las Cortes Colombianas; por lo que resulta importante conocer los fallos judiciales proferidos por los Tribunales de Arbitramento cuya sede tuvo lugar en el Centro de Conciliación, Arbitraje y Amigable Composición de la Cámara de Comercio de Neiva, por ser el único Centro de Arbitraje en el Departamento del Huila, además de proyectarse como una herramienta académica de gran utilidad para toda la comunidad jurídica de la región.

Así las cosas, se planteó el siguiente problema jurídico:

¿Existen precedentes judiciales a partir de los fallos proferidos por los Tribunales de Arbitramento cuya sede ha tenido lugar en el Centro de Conciliación, Arbitraje y Amigable Composición de la Cámara de Comercio de Neiva, entre los años 2000 a 2010?

\section{OBJETIVOS}

\section{General}

Evidenciar los precedentes judiciales establecidos en los laudos en derecho proferidos por los Tribunales de Arbitramento, frente a las áreas del derecho de competencia del Centro de Conciliación, Arbitraje y Amigable Composición de la Cámara de Comercio de Neiva, entre los años 2000 a 2010.

\section{Específicos}

- Identificar el número de laudos proferidos durante el período indicado.

- Visualizar los problemas y fundamentos jurídicos de cada laudo.

- Evidenciar las áreas o especialización del derecho que generaron en mayor medida procedimientos arbitrales. 
- Identificar los medios de pruebas con mayor incidencia en cada caso.

- Determinar la cantidad de procedimientos que fueron habilitados por cláusula compromisoria y por pacto de compromiso.

- Analizar a la luz de la jurisprudencia de la Corte Constitucional, el desarrollo de algunos principios de la justicia arbitral, así como las causales de procedencia de la acción de tutela frente a los laudos arbitrales.

\section{METODOLOGÍA}

Toda vez que la investigación abordó una revisión jurídica y doctrinal de los laudos proferidos por los Tribunales de Arbitramento formados en la Cámara de Comercio de Neiva, entre los años 2000 a 2010, se procedió a su verificación mediante el trabajo de campo descriptivo, por lo que acorde a los objetivos que iluminan la pesquisa, el proyecto se desarrolló mediante el diseño de investigación CUALITATIVO y CUANTITATIVO, por cuanto se analizaron las propiedades del objeto de investigación y su caracterización, además de haberse utilizado herramientas como porcentajes, estadísticas entre otros.

En lo atinente a la problemática afrontada, se retornó a la llamada "sistematización", por cuanto la información que se analizó surge a partir de la elaboración de los pronunciamientos de laudos arbitrales, siendo para ello necesario recoger la temática propia de la justicia arbitral a través de la jurisprudencia proferida por la Corte Constitucional Colombiana, estudio que abarca el Principio de Voluntariedad y la Procedencia de la Acción de Tutela contra laudos arbitrales, al igual que la revisión doctrinal de la figura arbitral.

La sistematización ha pasado de ser una simple herramienta metodológica, para convertirse en un modelo de investigación, que hoy en día es reconocida y utilizada en diversas experiencias de trabajo social. Para el presente proceso investigativo, se trabajó inicialmente desde esta perspectiva como medio de producción de conocimientos.

Se entiende la sistematización como un proceso permanente, acumulativo, de creación de conocimientos a partir de la experiencia de intervención de una realidad social, como un primer nivel de teorización de la práctica. En este sentido, la sistematización representa una articulación entre teoría y práctica y sirve a objetivos de los dos campos. Por un lado, mejora la práctica; y de otra parte, aspira a enriquecer confrontar y modificar el conocimiento teórico actualmente existente, contribuyendo a convertirlo en herramienta realmente útil para entender y transformar la realidad. (Barnechea, González, y Morgan, 1992).

La pretensión por tanto de esta figura es producir una visión global y crítica de la información ya obtenida propiciando una estructura de comprensión accesible o posible de socializar, conformando así un medio de elaboración de conocimiento.

La población constituyó todos los laudos en derecho proferidos entre el año 2000 a 2010, y la muestra fue el $100 \%$ de la población.

\section{MARCOTEÓRICO}

En Colombia, el Estatuto de los Mecanismos Alternativos de Solución de Conflictos (M.A.S.C.), define el arbitraje como un mecanismo por medio del cual las partes en conflicto, trasladan la resolución de la pugna a un número impar de personas naturales de carácter particular (Tribunal Arbitral), quienes temporalmente quedan investidos de Jurisdiccionalidad. (Colombia, Decreto 1818, 1998, art. 115).

De igual forma, en sentencia C-098 de 2001, la Corte lo resaltó como un mecanismo excepcional en el que las partes intervinientes, por la naturaleza transigible de sus derechos e intereses, disponen libremente el conocimiento del conflicto a un tercero particular quien transitoriamente ejerce justicia (Colombia, Corte Constitucional, 2001). El Doctor Marco Gerardo Monroy Cabra (1998), por su parte, enfatiza 
que es un método para resolver extrajudicialmente las controversias que puedan ocurrir, o que hayan surgido entre dos o más partes mediante la actuación de una o más personas (árbitro o árbitros), los cuales derivan sus poderes del acuerdo de las partes contractuales, así como del reconocimiento que la Ley hace de su función.

Uno de los elementos esenciales que se desprende de la definición legal, constitucional y doctrinal del arbitraje en el país, sin lugar a dudas, es el acuerdo de voluntades para dar inicio a esta justicia especializada; sin embargo, en el campo propio de la llamada habilitación dentro del marco internacional, el procedimiento arbitral puede originarse bajo dos formas: la primera; como la adoptó Colombia, a través de la potestad de las partes para acudir a la justicia arbitral, siempre que se traten de derechos negociables; algunos partidarios de éste planteamiento son Glasson, Tissier y Morel. (Monroy, 1998).

La segunda, se conoce como habilitación forzosa, la cual se presenta cuando, por mandato de la Ley, las partes son obligadas a acudir a la justicia arbitral, tal como lo sostienen, entre otros, el francés Mongalvy, Miranda y el jurista chileno, Aylwin Azócar. (Monroy, 1998).

Los seguidores de la segunda tendencia no excluyen la primera, simplemente admiten como válidas las dos.

Por último, la Corte Constitucional Colombiana en sentencia T-058 de 2009, estableció sus características básicas en el orden constitucional, de la siguiente manera:

(i)Es el ejercicio de la función pública de administrar justicia en cabeza de particulares habilitados para el efecto; (ii) tiene origen en la voluntad de las partes que deciden libremente someter sus diferencias a la decisión directa de árbitros; (iii) en consecuencia, su naturaleza es temporal y transitoria, pues las actuaciones arbitrales terminan una vez se da por solucionada la controversia; (iv) los fallos son en derecho 0 en equidad; y (v) el legislador tiene amplias facultades para definir los términos bajo los cuales se configura este tipo de justicia. (Colombia, Corte Constitucional, 2009).

\subsection{Naturaleza jurídica del arbitraje}

Debido a que la naturaleza jurídica del arbitraje es controversial, no se puede posicionar específicamente dentro de la clasificación del derecho positivo, -público o privado-, por lo que su naturaleza atiende a tres corrientes:

\section{Escuela Contractualista}

La teoría contractualista establece que el arbitraje consiste en un contrato basado en la voluntad de las partes, que delegan el arreglo de sus diferencias a un tercero neutral, llamado árbitro, por lo que el arbitraje tiene un carácter contractual $\mathrm{y}$, por tanto, privado. (Haderspock, 2012).

Los juristas italianos Rocco y Chiovenda, por ejemplo, sostienen que el arbitraje es el resultado del acuerdo voluntario entre las partes, ya que por reconocimiento legal, son ellas las que confieren poderes al árbitro para dirimir sus controversias y no el Estado el que realiza dicha delegación, razón por la cual, nunca se ha considerado al árbitro como un funcionario público y este tampoco ostenta facultades jurisdiccionales. (Sarmiento, 1999).

En tal sentido, el Doctor Jorge Hernán Gil Echeverry (2010), advirtió que los autores de esta escuela, basan sus argumentos en el convenio, elemento que según estos, es esencial para que se genere el proceso arbitral, por lo que en virtud al acuerdo entre las partes, consignado dentro de un contrato obligatoriamente por escrito, se da inicio al proceso arbitral, situación por la que se dice que el arbitraje es de naturaleza contractual de derecho privado.

Autores que sustentan esta teoría, según Gil, tienen en común en decir que el arbitraje no es un proceso, por lo que de allí se desprende que los árbitros no podrían ser investidos de jurisdicción y sus fallos por tanto no producirían los mismos efectos de las sentencias judiciales, debido a que estos terceros 
ejercen un mandato legal, es decir, una función parajurisdiccional o cercano a la jurisdicción de los jueces naturales, pero distinto a este.

\section{Escuela Procesalista}

Según esta corriente, el arbitraje es una institución de índole procesal, en consecuencia de orden público; tiene carácter de juicio, por lo que el árbitro cumple la función de juez y su laudo se equipara a la sentencia judicial, siendo por ende de naturaleza jurisdiccional. (Haderspock, 2012)

La tesis procesalista, basa su importancia ya no en el pacto inicial, sino en su procedimiento; si bien se trata de una actividad de derecho público procesal, su naturaleza debe enfocarse desde el punto de vista funcional y de eficacia práctico jurídico del laudo, en otras palabras, entre el laudo y la sentencia judicial no deben existir diferencias coyunturales y por ello su eficacia y prevalencia deben ser la misma.

Los árbitros, a partir de la noción de los defensores de esta escuela, no son mandatarios de las partes, sino jueces independientes que resuelven un conflicto de intereses a través de laudos con efectos de cosa juzgada.

La misma Corte Constitucional adoptó esta corriente a través de la sentencia SU- 091 del 2000, al afirmar que el arbitraje es un procedimiento judicial, aunque tenga fundamento inmediato en un acuerdo de voluntades, y en sentencia C-330 del mismo año indicó que el arbitraje tal como ha sido concebido en nuestro ordenamiento jurídico, es una figura procesal, por ello en Colombia esta institución tiene el carácter de un proceso. (Gil, 2010, p. 113)

En sentencia T-716 de 1996, que dio trámite a la acción de tutela interpuesta contra la providencia del 29 de febrero de 1996, emitida por la Corte Suprema de Justicia, Sala de Casación Civil; la Corte Constitucional confirmó la línea jurisprudencial desarrollada por el Tribunal Supremo, al afirmar que es la Ley y no la voluntad de las partes el umbral del cual se desprenden los poderes jurisdiccionales de los árbitros, argumento fundado en el artículo 116, inciso 4 de la Constitución Política de Colombia.

\section{Escuela Ecléctica o Mixta}

Esta tendencia distingue dos etapas dentro de la figura arbitral, una necesariamente contractual, la cual se perfecciona mediante el pacto arbitral; y otra, totalmente procesal, originada en el conflicto de las partes contratantes, dando inicio de este modo al proceso arbitral.

Bajo esta tesis, el arbitraje tiene una doble naturaleza, nace de lo contractual al ser las partes quienes por acuerdo de voluntades lo pactan y termina siendo procesal, por ser la Ley la que otorga las facultades jurisdiccionales al árbitro para fallar con efecto de cosa juzgada y darle al arbitraje la calidad de proceso judicial.

La teoría mixta, también llamada conciliadora, considera el arbitraje como una institución sui generis, de naturaleza mixta o híbrida, en la que conviven, como un todo indisoluble, el origen contractual del mismo y la teología jurisdiccional que explica su aparición, institución contractual por su origen y procesal por sus efectos. (Haderspock, 2012).

Finalmente, como se anotó anteriormente, la Corte Constitucional ha tomado una posición netamente procesalista, al expresar que sin importar su nacimiento contractual, se trata de un verdadero proceso, debido a las facultades jurisdiccionales otorgadas por la Ley y el efecto de cosa juzgada que ostentan sus fallos judiciales.

Los elementos de la justicia arbitral en el Ordenamiento Jurídico Colombiano son los siguientes:

- Es de naturaleza procesal, por cuanto a pesar de su carácter transitorio, los árbitros ejercen una función jurisdiccional.

- Se origina por la voluntad expresa de las partes del conflicto, por ser requisito esencial la cláusula compromisoria o pacto de compromiso.

- Los asuntos generadores del conflicto necesariamente son transigibles, es decir transferibles a 
terceros o negociables.

- Los fallos proferidos en derecho o en equidad tienen efecto de cosa juzgada.

\subsection{Clasificación del arbitraje en Colombia}

Desde el punto de vista doctrinal, la clasificación del arbitraje en Colombia se desarrolla bajo varias premisas, por ejemplo para el Doctor Jorge Hernán Gil Echeverry (2010), en cuanto a los principios el arbitraje se clasifica en Derecho, Equidad y Técnico.

Legalmente el Estatuto Orgánico de los Métodos Alternos de Solución de Conflictos, Decreto 1818 de 1998, en cuanto al procedimiento, el cual depende exclusivamente de la elección de las partes, puede ser Independiente, es decir, cuando las partes pactan de manera voluntaria y libre las reglas de procedimiento que el árbitro debe aplicar para la resolución de su conflicto; Institucional, cuando aquellas se someten a las reglas de procedimiento establecidas por un Centro de Arbitraje Nacional; y Legal, cuando se desarrolla con la normatividad vigente, por no haberse remitido a un procedimiento especial.

\subsection{Principios en el arbitraje}

La Carta Constitucional es el marco legal del Ordenamiento Jurídico Nacional, es la ley de leyes, por ello no existe procedimiento alguno que se escape de los principios contenidos en esta Carta política y social, ya que el deber de un Estado Social de Derecho siempre debe ir encaminado a la protección del ser humano y del interés social, por esto el arbitraje como todo procedimiento jurisdiccional tiene una fuente constitucional, el cual se encuentra consagrado en el artículo 116 de la Constitución Política, con el fin de dar cumplimiento a uno de los objetivos del Estado Colombiano, la administración de justicia.

El primer principio constitucional es la Jurisdiccionalidad, entendida como la facultad de administrar justicia, función que se encuentra en cabeza del
Estado, pero que por vía constitucional ha sido otorgada de forma transitoria a un tercero particular (árbitro), constituyéndose en una jurisdicción especial e independiente de la justicia común. En tal sentido la Corte Suprema de Justicia, Sala Plena, mediante sentencia del 21 de marzo de 1991, esclareció que dicha función no la proveen las partes por cuanto estas carecen de la misma, por ser una obligación esencial del Estado. (Gil, 2010).

Según Gil (2010) la actividad del arbitraje en Colombia es de naturaleza procesal, pues en virtud del principio jurisdiccional los árbitros deben sujetarse a los principios contenidos en la Constitución y la Ley tales como el Debido Proceso, Igualdad de las partes en el proceso, contradicción de la prueba, derecho de defensa, entre otros; quedando en un plano de igualdad frente a los jueces de la República.

Unos de los principios más importantes dentro de la justicia arbitral es la Habilitación, ya que son las partes del conflicto que de forma voluntaria trasladan la competencia a un tercero particular llamado árbitro, para que este a través de un verdadero proceso, resuelva o dirima el conflicto en derecho 0 en equidad, según sea el caso, es decir, son las partes contractuales quienes habilitan al árbitro para el ejercicio de la función jurisdiccional. (Colombia, Corte Constitucional, C-431/1995).

Es claro que en Colombia no existe el arbitraje forzoso, sino por el contrario, el procedimiento arbitral se enmarca dentro del principio constitucional de la Voluntariedad. La misma Corte Constitucional se ha pronunciado frente a este principio en varias ocasiones al enfatizar que una condición indispensable para que los particulares ejerzan la función pública de impartir justicia debe ser la habilitación que generan las partes a través de un acuerdo voluntario en la elección del arbitraje como mecanismo alterno para la solución de sus controversias, siguiendo en este sentido la teoría contractualista, pues indudablemente es a través del pacto de compromiso o cláusula compromisoria el medio por el cual se expresa dicha voluntad para el 
ejercicio de la jurisdicción. (Colombia, Corte Constitucional, C-060/2001)

Por último, como en todo procedimiento es imperante el Principio de Legalidad, toda vez que es el legislador como cuerpo colegiado de elección popular el que debe disponer, restringir o modificar la técnica arbitral, siempre siguiendo como marco de referencia los principios constitucionales. (Colombia, Corte Constitucional, C-294/1993 y C-242/1997)

\subsection{Laudo arbitral}

Es la decisión que profiere un Tribunal de Arbitramento frente a un conflicto sometido a su consideración, el cual deber ser sustentado con razonamientos congruentes a la situación jurídica que se pretenda resolver, sea en equidad 0 en derecho.

Según expreso mandamiento del Decreto compilador del arbitraje, el laudo debe justificarse, es decir, la decisión jurídica tomada tiene que ser debidamente motivada:

El laudo se acordará por mayoría de votos y será firmado por todos los árbitros, aún por quienes han salvado el voto y por el secretario; si alguno se negare, perderá el saldo de los honorarios que le corresponde, el cual se devolverá a las partes. El árbitro disidente consignará en escrito independiente los motivos de su discrepancia. (Colombia, Decreto 1818,1998 , art. 158)

En cuanto al contenido del mismo, el Decreto 1818, no contiene pautas de cómo debe ser expedido este, por ende, debe inferirse que si el laudo arbitral, tiene los mismos efectos de una sentencia judicial, se rige por los artículos: 303 y 304 , del estatuto procesal civil colombiano; por ende el laudo arbitral debe tener una parte motiva y otra resolutiva.

Respecto a la constitución del Tribunal de Arbitramento, expresamente el Decreto referido ordena que el número de árbitros sea impar, para evitar los posibles empates, ya que en el caso Colombiano no se contempla la posibilidad de designar árbitros dirimentes o que quebranten la igualdad.

Como obligación legal, dentro del Ordenamiento Jurídico Colombiano, todo laudo arbitral debe ordenar su protocolización ante una notaría del lugar donde se instaló y funcionó el Tribunal de Arbitramento; requisito que fue establecido en el artículo 159 del Decreto 1818, que compiló el artículo 35 del Decreto 2279 de 1989, basado en que el laudo debe quedar al alcance de las partes a fin de que puedan solicitar copia del mismo, ya que el citado Decreto no impuso la obligación a los Centros de Arbitraje de llevar su archivo, igualmente el fallo arbitral tiene que inscribirse cuando afecte bienes sujetos a registro.

\section{PRECEDENTES JURISPRUDENCIALES DE LA CORTE CONSTITUCIONAL}

\section{Principio de la Voluntad.}

Con respecto al principio de la voluntad de las partes; dentro de los pronunciamientos que ha realizado la honorable Corte Constitucional Colombiana ya sea en sede de revisión de tutela 0 en acciones constitucionales, se tomó como sentencia hito la SU174 de 2007, por cuanto en esta providencia, la Corte realiza un extenso estudio jurídico y doctrinal acerca del origen voluntario de la vía arbitral para resolver conflictos y la naturaleza jurisdiccional del arbitraje, resaltando sus fundamentos constitucionales, así mismo su postura frente a los límites que pesan sobre los asuntos que son susceptibles de resolución por un tribunal arbitral, y los sujetos que pueden recurrir al arbitramento para resolver sus disputas. También hace énfasis en la denominada fuerza vinculante del laudo arbitral y la restricción en las vías judiciales para controvertirlo, con el fin de explicar las hipótesis de procedencia excepcional de la acción de tutela contra laudos arbitrales.

El principio de voluntariedad para el acceso a la justicia arbitral en el examen constitucional, 
encuentran su origen y desarrollo en las sentencias C-294 y C-431 de 1995, la C-242 de 1997, C-1140 de 2000, C-060 y C-098 de 2001, C-1038 de 2002 y C-378 de 2008; jurisprudencias que constituyen toda una línea recta de precedentes, cuya característica común, es la importancia que le imprime la Corte a la autonomía de las partes como fundamento del nacimiento de cada proceso arbitral y el principio de habilitación hechas por las mismas, indicando incluso que el Legislador debe respetar dicha voluntad.

De la línea jurisprudencial referida, partiendo de la prohibición del arbitraje forzoso en el país; se evidencia como fuente, alcances o límites del principio de la Voluntad, lo siguiente:

Son contrarias a este principio esencial que determina el origen, los alcances, el ámbito y los efectos del arbitramento las normas legales que (i) imponen a los particulares en determinados contextos la obligación de acudir al arbitraje; (ii) exigen a ciertas empresas estatales someter las diferencias que puedan surgir en los contratos que celebran a procesos arbitrales; (iii) obligan a las partes en ciertos tipos de contratos a incluir una cláusula compromisoria; o (iv) atribuyen funciones arbitrales a entidades o individuos que no han sido expresamente habilitados por las partes en ejercicio de su voluntad libre y autónoma. (Colombia, Corte Constitucional, SU-174/2007).

\section{CAUSALES DE PROCEDIBILIDAD DE LA ACCIÓN DE TUTELA CONTRALAUDOS ARBITRALES}

La Corte Constitucional a través de las sentencias T- 608 de 1998, SU-058 de 2003, T-1228 de 2003, T-920 de 2004 y T-244 de 2007, ha indicado que el arbitraje como mecanismo alterno a la administración de justicia, emite pronunciamientos denominados laudos, lo cual, no por ser diferente a la justicia común deja de constituir una decisión jurisdiccional que sin lugar a dudas se equipara a las sentencias judiciales, por lo que al igual que estas la Corte ha destacado como sub-reglas específicas frente a la procedencia de laAcción de Tutela, lo siguiente:

(...) la Corte ha indicado que hay lugar a la interposición de la acción de tutela contra una decisión judicial cuando (1) la decisión impugnada se funda en una norma evidentemente inaplicable (defecto sustantivo); (2) resulta incuestionable que el juez carece del apoyo probatorio que permita la aplicación del supuesto legal en el que se sustenta la decisión (defecto fáctico); (3) el funcionario judicial que profirió la decisión carece, en forma absoluta, de competencia para hacerlo (defecto orgánico); y, (4) el juez actuó completamente por fuera del procedimiento establecido (defecto procedimental). Esta sustancial carencia de poder o de desviación del otorgado por la Ley, como reveladores de una manifiesta desconexión entre la voluntad del ordenamiento y la del funcionario judicial, aparejará su descalificación como acto judicial. (Colombia, Corte Constitucional, 2007).

La procedencia de este amparo constitucional contra una sentencia judicial, se produce con fundamento por lo menos en uno de estos cuatro defectos.

También delimitó los requisitos de procedibilidad de la acción de tutela frente a laudos arbitrales al disponer en sentencia T-244 de 2007, que el asunto objeto de debate sea de evidente relevancia constitucional, que se haya hecho uso de todos los mecanismos de defensa judicial -ordinarios y extraordinarios- a disposición del afectado, salvo que se trate de evitar un perjuicio iusfundamental irremediable, que se cumpla el requisito de la inmediatez y que la tutela se interponga en un término razonable y proporcionado desde el momento de ocurrencia de la vulneración del derecho fundamental, siempre que se trate de una irregularidad procesal, y que dicha irregularidad tenga un efecto decisivo en la sentencia objeto de controversia y afecte los derechos fundamentales de la parte actora.

En la solicitud del amparo tutelar se deben identificar los hechos que generaron la vulneración y los derechos afectados además de haberse alegado tal 
vulneración dentro del trámite arbitral, siempre que ello hubiere sido posible.

A pesar de la distinción que por Ley se hace al procedimiento arbitral, como un simple mecanismo que subsiste por fuera de la administración de justicia en cabeza del Estado, más allá de una herramienta, el arbitraje se consolida como una verdadera jurisdicción, tal cual al Derecho civil, administrativo, laboral, etc. Sin lugar a dudas los laudos arbitrales poseen los mismos efectos jurídicos que las providencias judiciales, así lo ha identificado la Corte Constitucional en varios de sus fallos, además, de la línea jurisprudencial analizada, referente a la procedencia de la acción de tutela contra laudos arbitrales, el alto Tribunal ha sido reiterativo al indicar las mismas pautas o requisitos de procedibilidad frente a las sentencias judiciales, dándole por tanto un trato igual.

\section{RESULTADOS DE LAINVESTIGACIÓN}

A continuación se presentan los resultados del estudio realizado a los laudos protocolizados en el círculo notarial de Neiva, capital del departamento del Huila, durante el periodo comprendido para el fin y propósito del presente estudio.

Ficha Técnica de Trabajo de Campo.

Para la recolección de la información trazada en los objetivos generales y específicos que iluminaron el desarrollo de la investigación, se elaboró como herramienta una ficha técnica para el trabajo de campo, constitutiva en 17 preguntas de las cuales 14 fueron cerradas y 3 abiertas.

Dentro del tiempo comprendido para el desarrollo de la investigación, es decir del año 2000 a 2010, tan solo seis (6) laudos arbitrales fueron protocolizados en las Notarías del círculo de Neiva. A parte que todos estos laudos trataron problemas jurídicos de diferente índole, por lo que las preguntas cerradas buscan determinar la costumbre o perspectiva que se tiene de la justicia arbitral en esta región del país, pero tan solo se tabularán las más relevantes para el presente análisis .

\subsection{Tabulación}

La encuesta para evidenciar las líneas jurisprudenciales que han surgido frente a diferentes áreas del derecho los cuales han sido estudiados y desarrollados por los Tribunales de Arbitramento cuya sede han tenido lugar en la Cámara de Comercio de Neiva, entre los años 2000 a 2010, se graficó de la siguiente manera:

1.Personas de derecho público o de derecho privado.

\begin{tabular}{|l|l|l|}
\cline { 2 - 3 } Gráfico 1. & Público & 1 \\
\cline { 2 - 3 } & Privado & 5 \\
\hline TOTAL & $\mathbf{6}$ \\
\hline
\end{tabular}

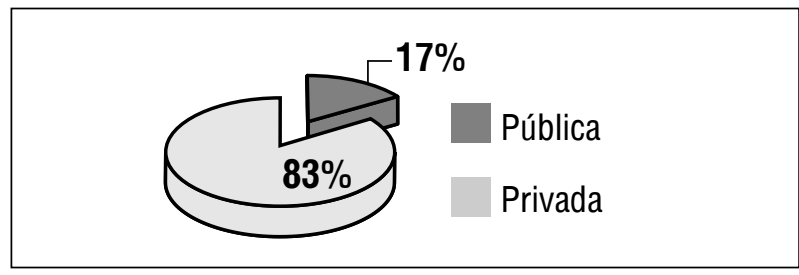

Del total del Laudos Arbitrales, el $83 \%$ de las partes fueron personas (naturales o jurídicas) de derecho privado y el $17 \%$ de personas jurídicas de derecho público.

La Ley 80 de 1993, en cuanto a la controversia contractual, dispuso en su búsqueda para la descongestión de los despachos judiciales posibilitar y promocionar los métodos alternativos de soluciones de conflictos orientada a los estándares de la Constitución de 1991, como los nuevos conceptos de administración y gobierno, dirigidos a que "las partes contratantes, solucionen directamente los problemas no litigiosos y las diferencias y discrepancias surgidas de la actividad contractual en el sector público, evitando en lo posible las vías judiciales". (Carnelutti, F., 1956).

Contrario a este querer, la tabla refleja una tendencia por parte de las entidades públicas hacia la administración de justicia en cabeza de la jurisdicción 
de lo contencioso administrativo para la resolución de sus conflictos.

\section{2 Área o especialización del Derecho}

\begin{tabular}{|c|c|c|}
\hline \multirow{4}{*}{ Gráfico 2.} & Administrativo & 1 \\
\hline & Comercial & 3 \\
\hline & Civil & 2 \\
\hline & TOTAL & 6 \\
\hline
\end{tabular}

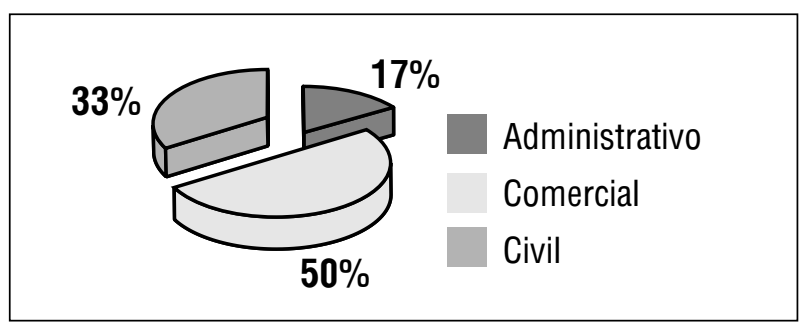

El $50 \%$ de los Laudos existentes en el periodo de estudio, han sido en el área del Derecho Comercial, el $33 \%$ en Derecho Civil y el $17 \%$ en Derecho Administrativo.

El por qué la mayoría de los laudos emanados por tribunales de arbitramento conformados en la Cámara de Comercio de Neiva, son de derecho comercial, tiene un origen transnacional y bastante antiguo. Se podría afirmar que el nacimiento del arbitraje como método de solución de controversias se produjo a la par del desarrollo del propio Derecho Comercial; Aylwin Azocar (1983), afirma que en la edad media los burgueses, artesanos y comerciantes buscaban justicia a través del arbitraje en sus gremios y corporaciones. (Monroy, 1998)

Es innegable que la mayoría de las controversias dirimidas por los Tribunales de Arbitraje en el Departamento del Huila superan los 100 millones de pesos, tal como se evidencia en la tabla de resultados (Pregunta 8), cuantía que por lo general por razonamiento lógico es manejado por empresas del sector privado.

\subsection{Pruebas practicadas}

Gráfico 3.

\begin{tabular}{|l|l|l|l|}
\hline Documentales & 6 & Inspección Judicial & 4 \\
\hline Testimoniales & 6 & Dictamen Pericial & 4 \\
\hline Interrogatorios & 4 & TOTAL & $\mathbf{2 4}$ \\
\hline
\end{tabular}

Documentales
Testimoniales
Interrogatorios
Inspección Judicial
Dictamen Pericial

Dentro de las pruebas practicadas en los procesos arbitrales, el $25 \%$ han sido documentales y testimoniales y el $17 \%$ fueron interrogatorios, inspección judicial y dictamen pericial.

Si bien el estatuto arbitral remite el régimen probatorio al estatuto procesal civil, se puede afirmar que los principios que rigen la teoría general de la prueba, se cumplen en este método de solución de controversias, en mayor medida que en el proceso judicial, debido a que el árbitro tiene un acercamiento directo con la prueba en su ejercicio procesal. La tabla denota a simple vista que no hay como tal una prueba determinante 0 fija que sobrepase los diferentes medios probatorios otorgados por el ordenamiento de procedimiento civil, pues son diversos y usuales todos los permitidos dentro del ordenamiento jurídico colombiano.

\subsection{Medio por el cual se pactó el arbitraje}

\section{Gráfico 4.}

\begin{tabular}{|l|l|}
\hline Cláusula & 6 \\
\hline Pacto & 0 \\
\hline TOTAL & $\mathbf{6}$ \\
\hline
\end{tabular}

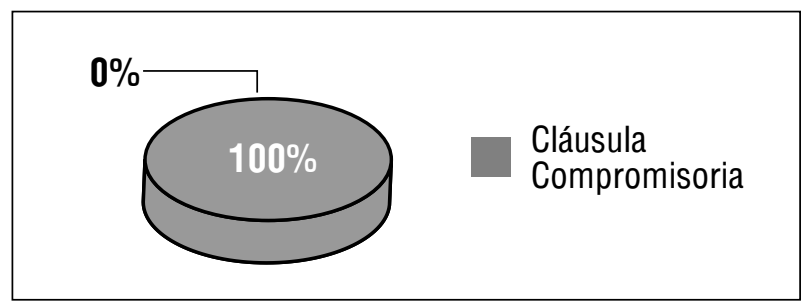


El $100 \%$ de los fallos de Laudos Arbitrales, se pactaron por medio de cláusula compromisoria.

Los laudos que se encontraron en el espacio temporal del presente objeto de estudio, surgen de un contrato que previó sobre la existencia de un futuro conflicto, lo que demuestra que no hay voluntad para que las partes en un pos conflicto busquen acceder al proceso arbitral por medio del pacto de compromiso, por cuanto la costumbre encamina a los potenciales usuarios hacia la administración de justicia ordinaria y a otros métodos de solución de conflictos. A parte que los contratos en su gran mayoría ya contienen prediseñados, cláusulas compromisorias.

\section{CONCLUSIONES}

Alo largo del trayecto investigativo se pudo constatar que la tendencia tanto de los particulares como de la administración pública es la de acudir a la justicia ordinaria, habida cuenta que durante el período comprendido entre el año 2000 a 2010, tan solo existen 6 laudos arbitrales y todos ellos originados por el Derecho privado, situación que indica la falta de convicción tanto de las entidades públicas como del ciudadano hacia este mecanismo alternativo de solución de conflictos.

Ahora bien, una vez sometido el pleito a la justicia arbitral, pudo evidenciarse que dentro de las pruebas más practicadas por los árbitros para la solución del litigio se encontraron las documentales en primera instancia, las testimoniales y finalmente la inspección judicial, situación que refleja que a pesar de existir libertad probatoria en este campo, los medios de prueba más utilizados siguen siendo las mismas practicadas en el derecho positivo.

Otro de los resultados obtenidos dentro de la presente investigación y que llama mucho la atención es que ninguna de las controversias terminó en audiencia de conciliación, lo cual supone que a estas instancias las partes prefieren que sea un tercero quien dirima sus conflictos.
Finalmente y como quiera que la presente investigación se orientó a responder sobre la existencia de precedentes a partir de los laudos proferidos entre el año 2000 a 2010, se debe valorar en primer lugar, el último concepto emitido por la Corte Constitucional sobre precedente judicial:

El precedente jurídico es aquel antecedente del conjunto de sentencias previas al caso que se habrá de resolver, que por su pertinencia para la resolución de un problema jurídico, debe considerar necesariamente un juez o una autoridad determinada, al momento de dictar sentencia. (Colombia, Corte Constitucional, T-762/11).

Así es como el precedente debe ser anterior a la decisión donde se pretende su aplicación y debe existir una semejanza de problemas jurídicos, cuestiones constitucionales, hechos del caso, normas juzgadas o puntos de derecho. En ausencia de uno de estos elementos, no puede predicarse la aplicación de un precedente. (Colombia, Corte Constitucional, T-762/11).

Al recordar que jurisprudencialmente se ha indicado que el laudo arbitral refleja la decisión, fallo 0 sentencia, por cuanto es la resolución del problema jurídico o el punto del derecho por el cual han sido convocados los Tribunales de Arbitramento; en el transcurso de esta investigación surgió el siguiente interrogante: ¿Es posible el establecimiento de un precedente en la justicia arbitral si comparativamente se habla de la noción de Laudo como una Sentencia judicial de la administración de justicia?.

Al solucionar este problema se encontró que respecto a la justicia arbitral encomendada a los Centros de Arbitramento, la creación de precedentes judiciales, en el espacio temporal dentro del cual se desarrolla dicha justicia especial obedece 1) al uso que haga la población de este mecanismo, 2) al número de laudos que se hayan proferido en un determinado espacio temporal, 3) la semejanza en los problemas jurídicos, fácticos o los puntos de derecho que permitan inferir en una futura decisión, y 4) el conocimiento que tengan los árbitros de los 
laudos proferidos en su centro de arbitraje.

Es así, que de los resultados arrojados por la investigación, se descarta por completo la presencia de precedentes jurídicos en cualquier área objeto de conocimiento por el Centro de Conciliación, Arbitraje y Amigable Composición de la Cámara de Comercio de Neiva, toda vez que el número de laudos proferidos y protocolizados en el círculo notarial de Neiva, entre los años 2000 a 2010 (6 en total), no cumplen los presupuestados anteriormente señalados, debido al poco uso que hace la población de este mecanismo, el número bajo de laudos protocolizados dentro de un período de tiempo tan amplio como el determinado para este estudio, y sin duda alguna la falta de conocimiento que tienen los árbitros sobre los laudos proferidos en ese Centro de Arbitraje, lo cual obedece a la estipulación legal sobre el archivo de estos fallos por parte de las notarías circunscritas.

Solución a lo anterior, obedecería a una implementación de estrategias por parte del Gobierno central y Departamental dirigidas a fomentar el uso de este mecanismo por parte de la comunidad, tendientes además a desarrollar un lenguaje no conflictivo sino conciliatorio para soluciones ágiles y equitativas.

De igual modo, se cree necesaria la promulgación de un verdadero estatuto de procedimiento arbitral, por cuanto se prevé, dirima conflictos nacionales y transnacionales, tras la entrada en vigencia de varios tratados de libre comercio lo cual generará en mayor medida relaciones contractuales susceptibles de arbitraje.

En este sentido y no menos importante, los árbitros aun cuando son investidos transitoriamente de jurisdiccionalidad, deben disponer de una base de datos digital, tal como la de las altas cortes colombianas, que contengan sus fallos, lo cual permitirá en un futuro la construcción de precedentes judiciales y la consolidación de esta justicia dentro de la región surcolombiana.

\section{REFERENCIASBIBLIOGRÁFICAS}

- Azula Camacho, J. (1998). Manual de Derecho Procesal Civil. (T. V. P. 331). Bogotá: Editorial Temis.

- Barnechea, M., González, E. \& Morgan, M. (1992). Taller Permanente de Sistematización de CEAAL - Perú. ¿Y cómo se hace? Propuesta de método de sistematización: Lima.

- Carnelutti, F. (1956). Sistema de Derecho Procesal Civil. (T. 1). Unión Tipográfica. Buenos Aires: Hispanoamericana (UTEHA).

- Monroy Cabra, M. (1998). Arbitraje comercial nacional e internacional. ( $2^{\mathrm{a}}$ ed.) Bogotá: Legis editores S.A.

- Gil Echeverry, J. (2010). Nuevo régimen de arbitramento - Manual práctico. (4a ed.) Bogotá: Cámara de Comercio de Bogotá.

- Sarmiento Sosa, C. (1999). Ley de Arbitraje Comercial. Caracas-Venezuela: LIVROSCA. C.A.

- Azocar, A. (1984). Relación de la Comisión de Derecho Administrativo. Revista Chilena de Derecho. Vol. 11, No. 213. pp. 519-522.

\section{JURISPRUDENCIALES}

CConst, T - 762/2011, M. Calle.

CConst, T-058/2009, J. Araujo.

CConst, C-378/2008, H. Sierra.

CConst, T - 244/2007, H. Sierra.

CConst, SU - 174/2007, M. Cepeda.

CConst, T- 920/2004, M. Monroy.

CConst, T - 1228/2003, A. Tafur.

CConst, SU - 058/2003, E. Montealegre.

CConst, C - 1038/2002, E. Montealegre.

CConst, C - 098/2001, M. Sáchica.

CConst, C - 060/2001, C. Gaviria.

CConst, C - 1140/2000, J. Hernández.

CConst, SU-091/2000, A. Tafur.

CConst, C - 330/2000, C. Gaviria.

CConst, T-608/1998, V. Naranjo.

CConst, C - 242/1997, H. Herrera.

CConst, T - 716/1996, A. Barrera.

CConst, C - 431/1995, H. Herrera.

CConst, C - 294/1995, J. Arango.

CConst, C - 294/1993, CConst Plena

CConst, T-762/1992, M. Calle 
NORMATIVAS

CN (2010), Legis.

CPC. (2011). Temis.

CCo. (2008). Temis.

D. $2279 / 1989$

D. $1818 / 1998$

D. $2651 / 1991$

D. $410 / 1971$
D. $1400 / 1970$

L. 23/1991

L. 80/1993

L. 270/1996.

L. 446/1998

L.446/1998

L.270/1996

L.80/1993 